This is an Accepted Manuscript of an article published by Taylor \& Francis in "Journal of Essential Oil Research" on $19^{\text {th }}$ February 2018, available online:

https://www.tandfonline.com/doi/abs/10.1080/10412905.2018.1435427 


\title{
Relationship between the terpene enantiomeric distribution and the growth cycle of lemon fruit and comparison of two extraction methods
}

\author{
Marta Guadayola ${ }^{a}$ Josep M. Guadayol ${ }^{b}$, Eulàlia Vendrella, Francesc Collgrós ${ }^{a}$ and Josep Caixach ${ }^{c}$ \\ ${ }^{a}$ Functional Food Research Department, Dallant, S.A., Barcelona, Spain; ${ }^{b}$ Chemical Engineering Department, Universitat Politècnica de Catalunya,
} Terrassa, Spain; 'Mass Spectrometry/Organic Pollutants Laboratory, IDAEA-CSIC, Barcelona, Spain

ABSTRACT

Lemon essential oil is one of the most widely used natural flavours in the food and beverage industries. Knowledge of the enantiomeric ratio in flavours has gained relevance because they may indicate differences in their organoleptic characteristics or their authenticity. The study was carried out during the growth of the lemon fruit to evaluate the possible variations of the enantiomeric ratio of four characteristic terpenes: $\alpha$-pinene, $\beta$-pinene, linalool and limonene. Two extraction methods were applied to extract the terpenes: simultaneous distillation-extraction at reduced pressure (V-SDE) and solid-phase microextraction; the results were equivalent whatever the method applied. In both cases, the target compounds were obtained from the lemon peel. Enantiomeric profiles were obtained by enantioselective multi-dimensional gas chromatography-mass spectrometry (enantio-MDGC-MS). Consistent enantiomeric ratios of a-pinene, $\beta$-pinene and limonene were observed; however, the enantiomeric ratio of linalool varied significantly according to the growth stage of the lemons in a spontaneous and natural way.
ARTICLE HISTORY

Received 3 August 2017

Accepted 23 January 2018

\section{KEYWORDS}

Lemon fruit; linalool; SPME; V-SDE; enantiomeric distribution; enantio-MDGCMS

\section{Introduction}

Citrus limon (L.) is a tree belonging to the family Rutaceae that produces lemon fruit (hereafter called lemon). Lemon essential oil, which is generally obtained by cold-pressing lemon rinds, is widely used as a flavouring agent by the food and beverage industries and is also used by the pharmaceutical and fragrance industries (1). The composition of the volatile fraction of lemon oil has been well studied and characterized. This fraction is mainly composed of monoterpenes and sesquiterpenes, among which limonene is the major constituent, plus other volatile components, including aldehydes, ketones, acids, alcohols and esters (2-5).

In the field of flavours and fragrances, the interest in the study of enantiomeric distributions has increased because enantiomers can differ in their odour quality and odour threshold (6-8). Moreover, the enantiomeric distribution is important because the chirality of its components can help to define the biosynthetic pathway of a component of a vegetal matrix and determine the authenticity or a possible adulteration of a product (9-11). In addition, enantiomers may present different bioactivity (12)
The aromatic profile depends on many factors, such as the genotype, chemotype, climatic conditions, season of growth, the part of the plant from which the volatile fraction was derived, among other factors, and may affect the flavour intensity (13). In case of assessing the authenticity of flavouring on the basis of its enantiomeric composition, knowing the consistency of this composition in nature is essential (14). Some studies have focused on the variation of the essential oil composition and its enantiomeric composition according to the season (15-17), but to our knowledge, none have evaluated the dependence of the enantiomeric distribution on the growth cycle of a lemon fruit. Citrus fruits have three well-defined growth stages. During the stage I, which lasts approximately two months, cell division and slow growth occur. During stage II (four- to six months long), the fruits undergo a large increase in size due to water accumulation as well as cellular growth. Finally, during stage III (approximately seven months long), the rate of growth slows and the fruits begin a ripening process during which their colour changes from green to yellow $(18,19)$.

The process used to extract an essential oil, as well as the analytical method applied, may modify the enantiomeric 
distribution of monoterpenes. One option to avoid any change in the purity of the original enantiomers is to study the lemon fruit directly to prevent racemization. Techniques such as purge and trap (P\&T), simultaneous distillation-extraction (SDE, also known as LikensNickerson method), liquid-liquid extraction (LLE), solid-phase microextraction (SPME) and stir-bar sorptive extraction (SBSE) methods have been widely applied to isolate and/or concentrate the volatile and semivolatile organic compounds (hereafter called VOCs) of essential oils and fruit samples. Enantioselective multi-dimensional gas chromatography (enantio-MDGC-MS), first described by Schomburg and co-workers (20), is one of the most powerful techniques for accurately solving the individual enantiomers of chiral compounds within complex matrices. Due to the development of maltodextrin-based stationary phases for chromatographic columns, enantiomer separation has reached a very high level of efficacy (21-23).

The objectives of this study were to determine the enantiomeric ratios of $\alpha$-pinene, $\beta$-pinene, linalool and limonene in lemons during growth stages I and II and to compare two extraction methods, SPME and SDE at reduced pressure (hereafter called V-SDE). To prevent from any change in the composition of the four components studied, the aforementioned methods were applied to obtain these components from the lemon peel, without obtaining them from the lemon oil.

Enantio-MDGC was applied to separate and analyse the enantiomeric compounds. From the results obtained, any possible relationships between the chirality of the volatile compounds of the lemon and the different growth stages of the fruit were discussed.

\section{Materials and methods}

\subsection{Plant material}

More than 80 lemons from Catalonia (Spain), were collected from the same lemon tree (Citrus limon L. var Verna). Collection was carried out during the growth stages I and II, and between May and October, before starting the maturation process. Then, the lemons were analysed during the same day of collection or were stored frozen at $-18{ }^{\circ} \mathrm{C}$ until they were analysed.

\subsection{Reference compounds}

The reference compounds R-(-)-linalool, R-(+)-limonene, Sigma-Adrich (Buchs, Switzerland) with enantiomeric purities between 98 and $99 \%$. The racemic mixtures of linalool were purchased from Sigma-Aldrich (Buchs, Switzerland) and racemic mixture of limonene, $\alpha$-pinene

and $\beta$-pinene were supplied by Dallant S.A. (Sant Feliu 50 de Llobregat, Spain).

\subsection{Simultaneous distillation-extraction at reduced pressure (V-SDE) procedure}

With the goal of achieving a large surface/mass ratio and improving the rate of extraction, the lemon peels were removed from the fruits by scraping off very small pieces. Then, the pieces of lemon peel were weighed and placed in a 1-L flask to which $500 \mathrm{~mL}$ of double-distilled water were added. For extraction under reduced pressure, $5 \mathrm{~mL}$ of n-hexane from Sigma-Aldrich (Buchs, Switzerland) were placed in a $10-\mathrm{mL}$ flask. The solvent generally used at atmospheric pressure is a mixture of pentane and dichloromethane, although for extraction under reduced pressure, the use of a solvent with a higher boiling point than that of these compounds is advisable to prevent the loss of the solvent through the pumping system (24).

The flasks containing the solvent and the lemon samples to be extracted were linked to a Likens-Nickerson apparatus, which was assembled in the low-density solvent configuration (25). An electrically heated mantle was used to generate vapour distillation within the flask containing the sample. The flask containing the solvent was placed in a double-walled vessel and immersed in a polyethylene-glycol bath. This bath was heated using an external thermostatic system (Lauda, Lauda-Königshofen, Germany) that maintained the circulation of polyethylene glycol within the double wall, whereas the temperature of the bath was maintained using a feedback control system. These conditions were maintained throughout the 4-h extraction process.

A vacuum-pumping system (Telstar, Terrassa, Spain) was used to achieve an absolute pressure of $10.1 \mathrm{kPa}$. A Lauda (Lauda-Königshofen, Germany) cooling system was used; the temperature of the coolant (polyethylenglycol was also used) was maintained at $-18^{\circ} \mathrm{C}$ throughout the extraction process.

\subsection{Solid-phase microextraction extraction (SPME) procedure}

A set of experiments arranged through $2^{3}$ factorial design was used to optimize the extraction by SPME using the Minitab software (Minitab 16; Minitab Inc., Minneapolis, USA). All experiments were carried out in triplicate; in addition, an analysis of variance was also performed. The least significant difference at $p<0.05$ was calculated. Three factors were evaluated: temperature (40 or $60{ }^{\circ} \mathrm{C}$ ), extraction time (15 or $20 \mathrm{~min}$ ) and fibre coating (polydimethylsiloxane (PDMS) of $100 \mu \mathrm{m}$ film thickness and divinylbenzene/carboxen/polydimethylsiloxane or 
(DVB-CAR-PDMS) of 50/30 $\mu \mathrm{m}$ film thickness). Values of areas are shown as means in Table 1 . The best extraction temperature for $\beta$-pinene and limonene was $40^{\circ} \mathrm{C}$, while the best one for linalool was $60^{\circ} \mathrm{C}$; no differences were observed for $\alpha$-pinene when the two temperatures were applied. Extraction time had no significant influence on any of the four compounds; therefore, $20 \mathrm{~min}$ was the extraction time chosen. Regarding the fibre coating, PDMS fibre was more effective for $\beta$-pinene while no significant differences were found between the rest of the three other target compounds. Based on these results, SPME conditions applied were: $40{ }^{\circ} \mathrm{C}, 20 \mathrm{~min}$ and a $100 \mu \mathrm{m}$ layer of PDMS. A SPME holder and fibres from Supelco (Bellefonte, Pennsylvania, USA) were used to carry out the experiments.

To prevent racemization of the compounds under study, the VOCs were extracted from whole lemons using the SPME method. The lemon samples were placed into a flask of the appropriate volume, and the conditions previously described were applied. The fibres were conditioned prior to use by heating them at the injection port of the GC apparatus under the conditions recommended by the manufacturer. Owing to the large amount of terpenes of citrus fruit present in the glands of the flavedo, the surface of the lemons was perforated using a thin needle when needed to facilitate their release. After completing the extraction, the compounds were immediately desorbed from the fibre directly into the injector at $250^{\circ} \mathrm{C}$, using the splitless injection mode.

\subsection{Enantioselective multi-dimensional gas chromatography-mass spectrometry (enantio- MDGC-MS) analysis}

The enantio-MDGC-MS analyses were performed using two Varian CP-3800 chromatography systems (GC) that were connected to a Varian 4000 ion-trap mass spectrometer (ITMS) and using MS workstation 6.9 software (Varian, Walnut Creek, CA, USA).

The system consisted of a double oven. Using the optimal pneumatic adjustments, the selected fractions could be transferred from the first (achiral) column to the sec40 ond (chiral) column using a heated transfer line.

\subsection{1. $G C-1$}

The first chromatographic system utilized was equipped with a split/splitless 1079 injector (Varian) and a flame-ionization detector (FID). A Deans Valco valveless system directed the compound to the GC2 system via deactivated fused silica tubing. A VF1-ms non-polar 100\% dimethylpolysiloxane GC column (Varian, California; $15 \mathrm{~m} \times 0.25 \mathrm{~mm}$ i.d., $0.25-\mu \mathrm{m}$ thickness) was used. The injected volume was $1 \mu \mathrm{L}$ when injecting V-SDE extracts. The temperature program was $70^{\circ} \mathrm{C}$, held for $5 \mathrm{~min}$, and then increased to $125^{\circ} \mathrm{C}$ at $10{ }^{\circ} \mathrm{C} / \mathrm{min}$. Helium was used as a carrier gas at a constant pressure of $20 \mathrm{psi}$ in front injector and 16 psi in Deans switch; the split ratio was 1:10. The injector and FID temperatures were both $250^{\circ} \mathrm{C}$.

\subsubsection{GC-2}

The second chromatographic system was equipped with a split/splitless 1177 injector and a liquid CO2 capillary cold trap that froze the compounds before they entered the column. A cyclosil- $\beta$ capillary column $(30 \mathrm{~m} \times 0.25 \mathrm{~mm}$ i.d., $0.25-\mu \mathrm{m}$ thickness) coated with $30 \%$ hepatkis [2,3-di-Omethyl-6-O-t-butyl dimethylsilyl]- $\beta$-cyclodextrin in DB-1701 (J\&W Scientific, Agilent Technologies, Santa Clara, CA, USA) was used. The temperature program used for analysis of $\alpha$-pinene and linalool was $70^{\circ} \mathrm{C}$, held for $17 \mathrm{~min}$, and then increased to $220^{\circ} \mathrm{C}$ at a rate of $8^{\circ} \mathrm{C} / \mathrm{min}$ and the program for analysis of $\beta$-pinene and limonene was $70^{\circ} \mathrm{C}$, held for $26 \mathrm{~min}$, and then increased to $100^{\circ} \mathrm{C}$ at a rate of $10^{\circ} \mathrm{C} / \mathrm{min}$. The constant pressure was $20 \mathrm{psi}$.

\subsubsection{ITMS}

The electron ionization mass spectra of the compounds under study were recorded at $70 \mathrm{eV}$ of ionization energy. Using the full-scan mode, the mass range that was scanned was $30-200 \mathrm{~m} / \mathrm{z}$, at a rate at $0.5 \mathrm{~s} / \mathrm{scan}$. The temperature transfer line was maintained at $200^{\circ} \mathrm{C}$. Compounds were identified by comparing their mass spectra and retention times with those of the standard compounds. Additionally,

Table 1. Relative peak areas ${ }^{\mathrm{a}}$ of target compounds determined by SPME-GC-MS.

\begin{tabular}{|c|c|c|c|c|c|c|}
\hline \multirow{2}{*}{$\frac{\text { Variable }}{\text { fibre }}$} & \multirow[b]{2}{*}{$\mathrm{T}\left({ }^{\circ} \mathrm{C}\right)$} & \multirow[b]{2}{*}{$\mathrm{T}(\min )$} & \multicolumn{4}{|c|}{$\%$ peak area } \\
\hline & & & a-pinene & $\beta$-pinene & Limonene & Linalool \\
\hline PDMS & 40 & 15 & 1.384 & 1.839 & 79.117 & 0.072 \\
\hline DVB-CAR-PDMS & 40 & 15 & 1.901 & 1.436 & 80.355 & 0.091 \\
\hline PDMS & 60 & 15 & 1.619 & 1.834 & 68.888 & 0.115 \\
\hline DVB-CAR-PDMS & 60 & 15 & 1.157 & 1.286 & 73.268 & 0.146 \\
\hline PDMS & 40 & 30 & 1.450 & 1.636 & 79.464 & 0.077 \\
\hline DVB-CAR-PDMS & 40 & 30 & 1.792 & 1.459 & 77.870 & 0.100 \\
\hline PDMS & 60 & 30 & 1.527 & 1.785 & 68.970 & 0.112 \\
\hline DVB-CAR-PDMS & 60 & 30 & 1.323 & 1.442 & 74.887 & 0.116 \\
\hline
\end{tabular}

${ }^{\mathrm{a}}$ mean $(n=3)$. 


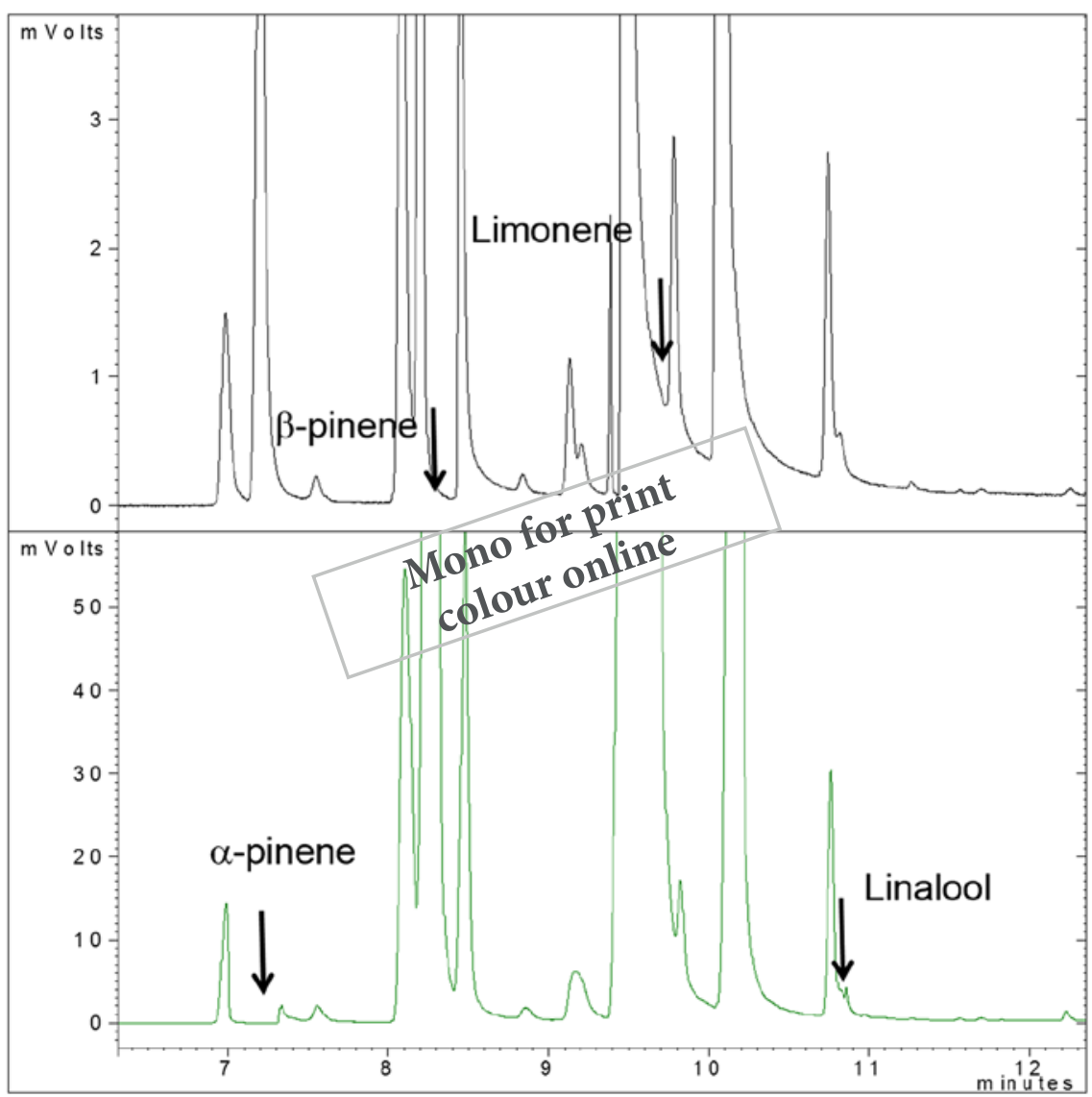

Figure 1. Total ion chromatogram (TIC) from real sample with the cuts of a-pinene, $\beta$-pinene, linalool and limonene.

the mass spectra of the compounds studied were compared to those in the NIST 2012 Library using MSView software. The order of elution of the enantiomers was obtained from data reported in the literature $(14,26)$ and obtained through analysis of the commercial standards.

\subsubsection{Statistical analysis}

All of the experiments were performed in triplicate. The mean values, the standard deviations (SD) and coefficients of variation $(\mathrm{CV})$ were determined. The mean values obtained for the experimental groups were compared using Student's $t$-test, with a $p$-value of $\leq 0.05$ considered significant.

\section{Results and discussion}

\subsection{Separation of target compounds}

The chiral compounds selected for this study were those that are most abundant in lemon fruit ( $\alpha$-pinene, $\beta$-pinene and limonene), as well as one of the principal odorant compounds (linalool) (27). As shown in Figure 1, two injections with two cuts each one were done, the first one to separate $\beta$-pinene from limonene and the second one to separate $a$-pinene from linalool. Figure 2 shows the TIC (total ion current) of the enantiomer pairs of $\alpha$-pinene and linalool. Figure 3 shows the TIC of the enantiomers of $\beta$-pinene and limonene. The two chromatograms were obtained from real samples studied in this work. When dealing with the separation of $\beta$-pinene and limonene, the cut was done very narrow in order to transfer only part of the sample due to the high concentration of limonene.

As stated in the previous section, two different temperature programs had to be optimized to obtain the maximum separation of the chiral compounds. The resolution of the enantiomer pairs of $\alpha$-pinene and $\beta$-pinene was improved using isotherms at $70{ }^{\circ} \mathrm{C}$. This higher initial temperature eliminated peak broadening. The peaks of $\alpha$-pinene and $\beta$-pinene were wider than those of limonene and linalool. This result was expected because a constant temperature can increase the peak width, whereas the peaks resolved under temperature ramping were narrower.

The resolution of the peaks of $\alpha$-pinene, $\beta$-pinene and limonene was greater than 1.5 and that of the linalool peak was 1.3. A long analysis time was required to achieve these levels of separation. 


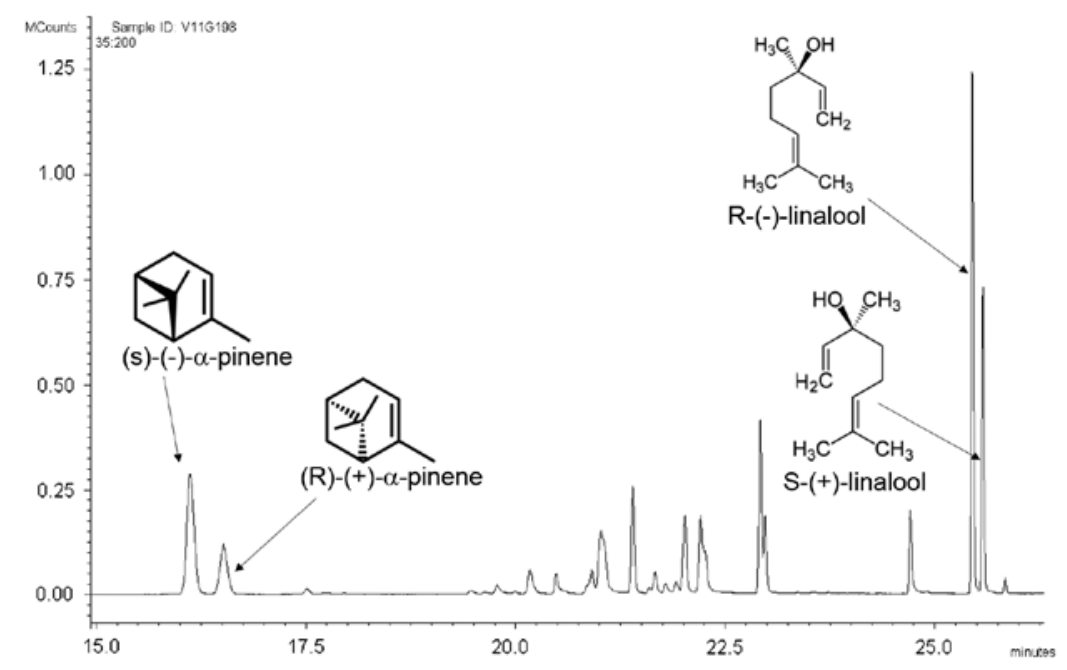

Figure 2. Total ion chromatogram (TIC) of a-pinene and linalool in lemon fruit, obtained using SPME enantio-MDGC-MS.

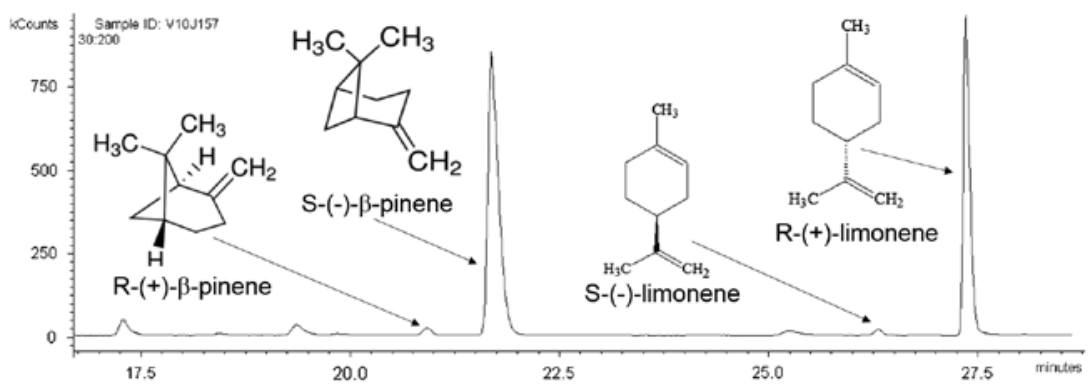

Figure 3. Total ion chromatogram (TIC) of $\beta$-pinene and limonene in lemon fruit, obtained using SPME enantio-MDGC.

\subsection{Comparison of the two extraction methods applied, V-SDE and SPME}

SPME is one of the recommended techniques to avoid racemization and generation of artifacts during processing, and it can be used to collect VOCs from live plants with minimal disturbance $(28,29)$. As stated before, to prevent from racemization when obtaining the lemon oil, SPME was directly applied to the entire lemon fruit. The percentage of the $\mathrm{R}$ enantiomers of $\alpha$-pinene, $\beta$-pinene, linalool and limonene that were extracted using SPME is shown in Table 2. Samples of lemons ranging from $0.1 \mathrm{~g}$ to approximately $160 \mathrm{~g}$ (stages I and II) were analysed. In addition, more lemon samples with larger size were analysed, but they were discarded because they had started ripening (stage 3 ).

SPME is a solventless and rapid method generating only one sample to be analysed whenever it is applied. Sometimes more than one analysis should be carried out and more amount of sample is necessary; this problem should be solved by V-SDE.

During SDE extraction at atmospheric pressure, the relatively high temperatures applied might cause a thermal generation of artefacts or racemization of some compounds $(14,30)$. To avoid this high-temperature-induced racemization, SDE at reduced pressure (V-SDE) 25 was tested.

The minimum amount of lemon submitted to V-SDE weighed at least $10 \mathrm{~g}$ due to the extraction characteristics. The lemons were first subjected to extraction using the SPME technique, and the same lemons were subsequently extracted using the V-SDE technique. The percentage of the $\mathrm{R}$ enantiomers of $\alpha$-pinene, $\beta$-pinene, linalool and limonene that were extracted using the V-SDE technique is shown in Table 3.

Although the VOCs were extracted at low temperatures using the V-SDE technique, the peels had to be scraped off and added to water. Subsequently, the medium may have become acidic, which would particularly affect linalool, but this does not occur because no significant differences between the percentage of $\mathrm{R}$ enantiomers of a-pinene, $\beta$-pinene, limonene and linalool obtained using SPME or V-SDE were observed (Figure 4(a) and (b)). Ruiz del Castillo et al. (2003) reported differences between the results obtained using SPME and SDE, but they employed SDE at atmospheric pressure. These results show that 
$6 \fallingdotseq$ M. GUADAYOL ET AL.

Table 2. Relative $\%$ of R enantiomer ${ }^{\mathrm{a}}$ in lemon fruit extracted by SPME.

\begin{tabular}{|c|c|c|c|c|c|c|c|c|}
\hline \multirow{2}{*}{$\frac{\text { Weight }(\mathrm{g})}{0.134}$} & \multicolumn{2}{|c|}{ a-pinene } & \multicolumn{2}{|c|}{$\beta$-pinene } & \multicolumn{2}{|c|}{ Limonene } & \multicolumn{2}{|c|}{ Linalool } \\
\hline & 25.201 & \pm 0.250 & 2.816 & \pm 0.039 & 98.302 & \pm 0.038 & 96.061 & \pm 0.099 \\
\hline 0.200 & 22.082 & \pm 0.074 & 3.366 & \pm 0.062 & 97.952 & \pm 0.246 & 95.426 & \pm 0.127 \\
\hline 0.210 & 24.915 & \pm 0.048 & 4.176 & \pm 0.214 & 99.998 & \pm 1.032 & 94.768 & \pm 0.148 \\
\hline 0.214 & 25.485 & \pm 0.037 & 6.048 & \pm 0.054 & 97.996 & \pm 0.092 & 93.366 & \pm 0.218 \\
\hline 0.550 & 30.646 & \pm 0.037 & 5.925 & \pm 0.165 & 98.153 & \pm 0.707 & 89.506 & \pm 0.196 \\
\hline 0.910 & 27.023 & \pm 0.425 & 4.766 & \pm 0.057 & 98.088 & \pm 0.029 & 94.346 & \pm 0.105 \\
\hline 1.139 & 27.055 & \pm 0.366 & 3.946 & \pm 0.063 & 97.994 & \pm .088 & 94.277 & \pm 0.201 \\
\hline 1.980 & 25.221 & \pm 0.186 & 5.544 & \pm 0.117 & 97.374 & \pm 0.145 & 93.546 & \pm 0.078 \\
\hline 2.810 & 25.651 & \pm 0.214 & 6.945 & \pm 0.014 & 95.331 & \pm 0.089 & 91.391 & \pm 0.374 \\
\hline 3.780 & 28.276 & \pm 0.387 & 3.852 & \pm 0.247 & 98.696 & \pm 0.247 & 92.824 & \pm 0.182 \\
\hline 4.238 & 29.330 & \pm 0.229 & 6.652 & \pm 0.130 & 97.796 & \pm 0.058 & 88.417 & \pm 0.146 \\
\hline 7.153 & 26.465 & \pm 0.092 & 5.547 & \pm 0.072 & 97.764 & \pm 0.050 & 87.256 & \pm 0.220 \\
\hline 10.307 & 27.611 & \pm 0.165 & 5.726 & \pm 0.052 & 97.752 & \pm 0.234 & 77.781 & \pm 0.019 \\
\hline 10.740 & 24.671 & \pm 0.130 & 5.726 & \pm 0.296 & 97.752 & \pm 0.179 & 86.741 & \pm 0.061 \\
\hline 13.943 & 24.722 & \pm 0.144 & 4.648 & \pm 0.273 & 97.945 & \pm 0.023 & 81.629 & \pm 0.147 \\
\hline 13.991 & 22.641 & \pm 0.291 & 5.279 & \pm 0.411 & 97.559 & \pm 0.104 & 78.447 & \pm 0.580 \\
\hline 20.760 & 24.461 & \pm 0.207 & 5.337 & \pm 0.158 & 97.199 & \pm 0.241 & 86.301 & \pm 0.368 \\
\hline 21.589 & 22.869 & \pm 0.239 & 5.279 & \pm 0.198 & 97.725 & \pm 0.178 & 80.720 & \pm 0.354 \\
\hline 21.860 & 26.087 & \pm 0.285 & 5.709 & \pm 0.147 & 97.010 & \pm 0.062 & 76.353 & \pm 0.561 \\
\hline 31.016 & 23.437 & \pm 0.353 & 5.918 & \pm 0.568 & 97.704 & \pm 0.058 & 84.709 & \pm 0.074 \\
\hline 32.294 & 26.045 & \pm 0.352 & 6.196 & \pm 0.021 & 97.587 & \pm 0.103 & 81.965 & \pm 0.796 \\
\hline 34.200 & 27.761 & \pm 0.464 & 6.302 & \pm 0.121 & 97.700 & \pm 0.038 & 81.792 & \pm 0.533 \\
\hline 39.700 & 26.258 & \pm 0.232 & 6.599 & \pm 0.184 & 97.602 & \pm 0.046 & 80.062 & \pm 0.303 \\
\hline 40.700 & 29.088 & \pm 0.643 & 6.936 & \pm 0.110 & 98.063 & \pm 0.012 & 72.683 & \pm 0.628 \\
\hline 40.800 & 27.080 & \pm 0.346 & 6.283 & \pm 0.097 & 97.660 & \pm 0.121 & 79.524 & \pm 0.265 \\
\hline 42.591 & 25.717 & \pm 0.153 & 6.078 & \pm 0.364 & 97.692 & \pm 0.030 & 84.892 & \pm 0.298 \\
\hline 45.311 & 26.238 & \pm 0.775 & 6.631 & \pm 0.329 & 98.053 & \pm 0.214 & 72.357 & \pm 0.790 \\
\hline 51.690 & 27.713 & \pm 0.331 & 6.092 & \pm 0.160 & 93.908 & \pm 0.995 & 77.010 & \pm 0.910 \\
\hline 57.620 & 27.829 & \pm 0.217 & 5.817 & \pm 0.325 & 97.981 & \pm 0.140 & 62.046 & \pm 0.843 \\
\hline 57.818 & 27.868 & \pm 0.861 & 6.430 & \pm 0.293 & 97.923 & \pm 0.070 & 72.258 & \pm 0.368 \\
\hline 59.510 & 26.777 & \pm 0.306 & 6.092 & \pm 0.230 & 97.864 & \pm 0.709 & 68.974 & \pm 0.974 \\
\hline 73.200 & 26.766 & \pm 0.326 & 6.790 & \pm 0.032 & 95.259 & \pm 0.236 & 71.138 & \pm 0.936 \\
\hline 82.700 & 28.971 & \pm 0.254 & 6.346 & \pm 0.015 & 97.064 & \pm 0.044 & 69.191 & \pm 0.684 \\
\hline 83.810 & 26.927 & \pm 0.065 & 6.492 & \pm 0.309 & 97.979 & \pm 0983 & 66.027 & \pm 0.236 \\
\hline 94.060 & 28.692 & \pm 0.456 & 6.886 & \pm 0.346 & 97.864 & \pm 0.073 & 64.757 & \pm 0.378 \\
\hline 96.159 & 27.455 & \pm 0.345 & 6.646 & \pm 0.052 & 98.486 & \pm 0.017 & 63.314 & \pm 0.896 \\
\hline 96.230 & 27.771 & \pm 0.802 & 6.070 & \pm 0.160 & 98.486 & \pm 0.043 & 64.513 & \pm 0.102 \\
\hline 106.200 & 29.903 & \pm 0.916 & 6.645 & \pm 0.417 & 96.704 & \pm 0.235 & 59.500 & \pm 0.504 \\
\hline 109.358 & 26.698 & \pm 0.032 & 6.346 & \pm 0.512 & 97.959 & \pm 0.879 & 62.909 & \pm 0.538 \\
\hline 110.468 & 26.908 & \pm 0.094 & 5.947 & \pm 0.390 & 96.533 & \pm 0.202 & 64.129 & \pm 0.325 \\
\hline 122.000 & 27.963 & \pm 0.356 & 6.002 & \pm 0.290 & 98.221 & \pm 0.320 & 59.727 & \pm 0.398 \\
\hline 130.000 & 27.532 & \pm 0.322 & 5.998 & \pm 0.326 & 98.146 & \pm 0.325 & 63.331 & \pm 0.452 \\
\hline 140.502 & 26.927 & \pm 0.062 & 6.646 & \pm 0.094 & 98.486 & \pm 0.125 & 66.027 & \pm 0.653 \\
\hline 152.136 & 28.060 & \pm 0.048 & 6.406 & \pm 0.631 & 98.179 & \pm 0.700 & 66.680 & \pm 0.155 \\
\hline 157.847 & 27.899 & \pm 0.785 & 7.045 & \pm 0.288 & 98.159 & \pm 0.262 & 64.629 & \pm 0.235 \\
\hline Mean & 26.638 & & 5.843 & & 97.681 & & 77.851 & \\
\hline Stand. dev & 1.859 & & 0.970 & & 0.956 & & 11.655 & \\
\hline
\end{tabular}

a \pm standard deviation (\%) $(n=3)$.

Table 3. Realtive $\%$ of R enantiomer ${ }^{\mathrm{a}}$ in lemon fruit extracted by V-SDE.

\begin{tabular}{|c|c|c|c|c|c|c|c|c|}
\hline \multirow{2}{*}{$\frac{\text { Weight (g) }}{10.740}$} & \multicolumn{2}{|c|}{ a-pinene } & \multicolumn{2}{|c|}{$\beta$-pinene } & \multicolumn{2}{|c|}{ Limonene } & \multicolumn{2}{|c|}{ Linalool } \\
\hline & 25.440 & \pm 0.600 & 5.262 & \pm 0.502 & 97.553 & \pm 0.100 & 85.518 & \pm 0.070 \\
\hline 20.760 & 24.547 & \pm 0.194 & 5.984 & \pm 0.186 & 97.749 & \pm 0.261 & 86.003 & \pm 0.242 \\
\hline 31.016 & 27.841 & \pm 0.410 & 6.419 & \pm 0.187 & 98.512 & \pm 0.874 & 80.531 & \pm 0.055 \\
\hline 32.294 & 28.245 & \pm 0.504 & 6.492 & \pm 0.089 & 97.979 & \pm 0.045 & 72.258 & \pm 0.208 \\
\hline 34.200 & 28.016 & \pm 0.160 & 6.042 & \pm 0.253 & 97.924 & \pm 0.253 & 81.298 & \pm 0.161 \\
\hline 40.800 & 27.535 & \pm 0.269 & 5.191 & \pm 0.563 & 97.736 & \pm 0.121 & 78.544 & \pm 0.265 \\
\hline 42.591 & 28.912 & \pm 0.410 & 6.282 & \pm 0.187 & 97.955 & \pm 0.142 & 79.308 & \pm 0.055 \\
\hline 51.690 & 26.896 & \pm 0.331 & 5.984 & \pm 0.160 & 96.523 & \pm 0.995 & 75.804 & \pm 0.910 \\
\hline 57.818 & 26.129 & \pm 0.111 & 6.196 & \pm 0.723 & 97.083 & \pm 0.029 & 74.364 & \pm 0.230 \\
\hline 73.200 & 26.910 & \pm 0183 & 6.178 & \pm 0.842 & 96.987 & \pm 0.236 & 70.984 & \pm 0.125 \\
\hline 82.700 & 27.236 & \pm 0.399 & 6.024 & \pm 0.328 & 98.024 & \pm 0.129 & 69.191 & \pm 0.236 \\
\hline Mean & 27.064 & & 6.071 & & 97.639 & & 78.346 & \\
\hline Stand. dev. & 1.283 & & 0.327 & & 0.567 & & 5.371 & \\
\hline
\end{tabular}

\footnotetext{
${ }^{\mathrm{a}} \pm$ standard deviation (\%) $(n=3)$.
} 

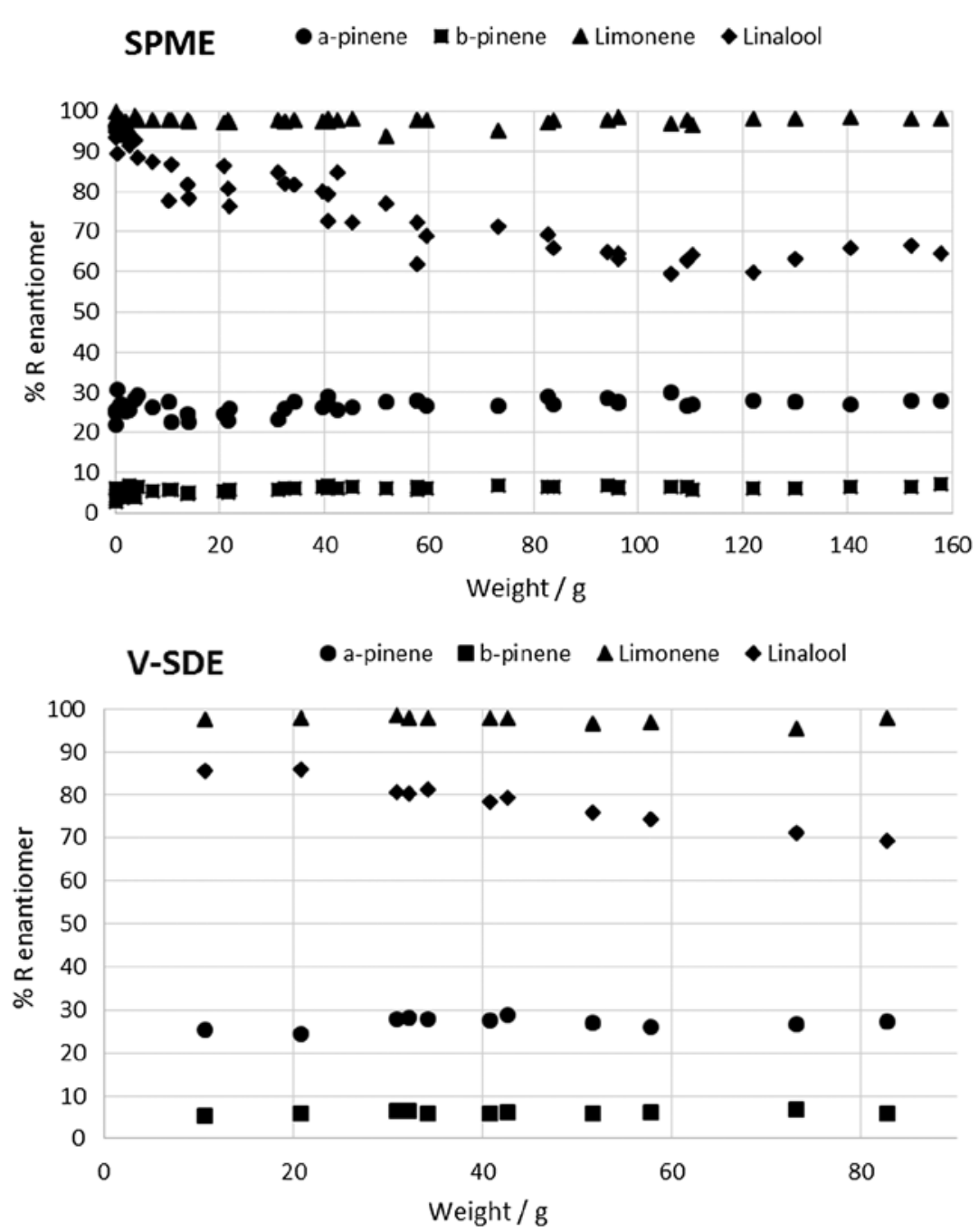

Figure 4. Variations in the percentage of the $\mathrm{R}$ enantiomers of $\alpha$-pinene, $\beta$-pinene, linalool and limonene according to the lemon weight when SPME (A) and V-SDE (B) were applied.

applying low pressure is essential to maintain the proper enantiomer distribution.

\subsection{Relationship between the enantiomer distribution and the growth cycle of lemons}

After checking the coincidence of the results obtained from both extraction methods, the discussion was mainly based on SPME; since this method requires a small amount of matrix (lemon). Due to the aforementioned reason, lemons with weight below $1 \mathrm{~g}$ could be extracted.

When the results obtained using both extraction techniques were analysed (Table 2), it was found that the $\alpha$-pinene, $\beta$-pinene and limonene enantiomer distributions of lemons did not nearly change during the growth cycle before the ripening stage was reached. Only, some slight variations can be detected in few of biggest lemons, probably because these fruits are in the beginning of maturation (stage 3). (S)- $\beta$-Pinene was the major $\beta$-pinene isomer ( $\mathrm{S}>94 \%$ ) and ( $\mathrm{R}$ )-limonene accounted for approximately almost $99 \%$ of the limonene enantiomer content. The enantiomeric ratio of (S)- $\alpha$-pinene to (R)- $\alpha$-pinene in lemon fruit was approximately 73:27. Consequently, these volatile compounds can be used as indicators of the origin of essential lemon oil. These data are consistent with those reported in the literature $(15,17)$. In contrast, the percentage of R-(-)-linalool decreased during the growth period, from 98 to $60 \% \mathrm{R}$. Therefore, linalool could not be considered a reference indicator.

Depending on their structures, compounds maybe more susceptible to generate their racemates. Based on the results shown in Figure 4(a) and (b), it can be inferred that linalool is a compound more likely to undergo structural changes, probably due to its open structure and a tertiary allylic alcohol, whereas $\alpha$-pinene, $\beta$-pinene and limonene have closed structures. Under specific conditions of $\mathrm{pH}$ and temperature, linalool may partially or completely racemise (31). Linalool is an excellent example 
of a molecule with different odours depending on its enantiomer: the (3S)-(+)-linalool (coriandrol) enantiomer has a sweet, floral, herbaceous and petitgrain-like scent with citrus and fruity notes, whereas the (3R)-(-)-linalool (licareol) enantiomer has a woody, lavender-like aroma (27). In addition, the odour threshold value of R-(-)linalool is approximately nine times lower than that of S-(+)-linalool (32).

Racemization may occur during processing, extraction and storage, as well as due to non-enzymatic reactions such as autoxidation, photo-oxidation and acidity, among others. Several studies demonstrated that the time of harvest affected the composition of essential oils $(13,16,33)$. Fluctuations in the enantiomer ratios in lemon oil according to the season of harvest have been studied (17).

In this work, the enantiomeric analyses were conducted without applying any type of prior treatment of the samples. This strategy allowed studying the direct relation between each enantiomer and the growth stage. In addition, the native profiles of the enantiomers could be studied.

There was a clear decrease in the R-linalool content as the lemons grew. The smallest lemon fruits in stage I contained more than $90 \% \mathrm{R}$ enantiomers (the lemon weights ranged from 0.1 to $2 \mathrm{~g}$ ). This value gradually decreased during stage II. When the lemon weighed approximately $60 \mathrm{~g}$, they contained $60 \% \mathrm{R}$ enantiomer. Because racemization did not occur during the extraction or analytical processes, it most likely occurred naturally during plant growth because the compounds were synthesized within an acidic matrix (31) or because of both biosynthetic pathways would have been operating (34).

The enantiomeric distributions of certain compounds can be used as a tool for detecting adulteration, provided that the enantiomeric ratios remain unchanged in nature and during the extraction process. For this purpose, studies on the stability of enantiomers have been performed. Some of these studies showed that the enantiomeric ratios of linalool, $\alpha$-phellandrene and $\beta$-phellandrene in lemon essential oil cannot be used as standard because a variable mixture of the two enantiomers of these compounds was always found (15). However, this is the first study to report the enantiomeric distribution of linalool at the birth of lemon fruit and how it evolves or varies during lemon fruit growth up to the point of maturation.

\section{Conclusions}

The results obtained from V-SDE method showed it as an excellent technique to extract monoterpenes from lemon fruits without any noticeable modification of their enantiomeric distribution. This conclusion was assessed after
By means of enantio-MDGC the study and evaluation of enantiomeric distribution of $\alpha$-pinene, $\beta$-pinene, linalool and limonene were carried out successfully during the lemon growth.

The consistency of the enantiomeric ratios of some of the chiral terpenes, such as $\alpha$-pinene, $\beta$-pinene and limonene, during the growth of a lemon fruit (before ripening) was demonstrated. And, the most important, the variability of the linalool enantiomeric ratio was showed. This evolution occurs naturally and spontaneously before beginning the maturation process.

The study of evolution of linalool provides new information about products obtained from lemon and added in various foodstuffs, contributing to a better understanding of enantiomers evolution during lemons growth meric biosynthesis of terpenes which allows studying the authenticity of lemon fruit.

\section{Chemical compounds studied in this article}

a-pinene (PubChem CID: 6654); $\beta$-pinene (PubChem CID: 14896); linalool (PubChem CID: 6549); limonene (PubChem CID: 22311).

\section{Acknowledgements}

We are grateful to Dallant, S. A. for the funding and collaborative efforts that allowed this study to be conducted. This work is in memory of our colleague and coauthor Francesc Collgrós.

\section{Disclosure statement}

No potential conflict of interest was reported by the authors.

\section{References}

1. P.Q. Tranchida, I. Bonaccorsi, P. Dugo, L. Mondello and G. Dugo, Analysis of Citrus essential oils: state of the art and future perspectives. A review. Flavour and Fragrance Journal, 27, 98-123 (2012).

2. F. Mehl, G. Marti, J. Boccard, B. Debrus, P. Merle, E. Delort, L. Baroux, V. Raymo, et al., Differentiation of lemon essential oil based on volatile and non-volatile fractions with various analytical techniques: a metabolomic approach. Food Chemistry, 143, 325-335 (2014).

3. J. Rao and D.J. McClements, Impact of lemon oil composition on formation and stability of model food and beverage emulsions. Food Chemistry, 134, 749-757 (2012).

4. M.-L. Lota, D. de Rocca Serra, F. Tomi, C. Jacquemond and J. Casanova, Volatile components of peel and leaf oils of lemon and lime species. Journal of Agricultural and Food Chemistry, 50, 796-805 (2002).

5. E. Dellacassa, D. Lorenzo, P. Moyna, A. Verzera, L. Mondello and P. Dugo, Uruguayan essential oils. Part VI. and, consequently, to a greater awareness of the enantiocomparing its results with those of SPME. 
Composition of lemon oil, flavour. Flavour and Fragrance Journal, 12, 247-255 (1997).

6. U. Ravid, Enantiomeric distribution of odorous oxygenated monoterpenes in aromatic plants. In: Sel. Top. Chem. Nat. Prod. Edits., R. Ikan, pp. 155-187. World Scientific, Singapore (2008).

7. E. Brenna, C. Fuganti and S. Serra, Enantioselective perception of chiral odorants. Tetrahedron: Asymmetry, 14, $1-42(2003)$.

8. L. Mondello, P. Dugo and G. Dugo, Citrus: the genus citrusthe chiral compunds of citrus essential oils. In Citrus: The Genus Citrus, First. Edits., A. Dugo and A. Di Giacomo, pp. 462-495, CRC Press, London (2003).

9. C. Bicchi, C. Cagliero and P. Rubiolo, New trends in the analysis of the volatile fraction of matrices of vegetable origin: a short overview. A review. Flavour and Fragrance Journal, 26, 321-325 (2011).

10. G. Dugo, I.S. d'Alcontres, M.G. Donato and P. Dugo, On the genuineness of citrus essential oils. Part XXXVI. Detection of added reconstituted lemon oil in genuine cold-pressed lemon essential oil by high resolution gas chromatography with chiral capillary columns. Journal of Essential Oil Research, 5, 21-26 (1993).

11. D. Juchelka, A. Steil, K. Witt and A. Mosandl, Chiral compounds of essential oils. XX. Chirality evaluation and authenticity profiles of neroli and petitgrain oils. Journal of Essential Oil Research, 8, 487-497 (1996).

12. M. Lis-Balcnin, R.J. Ochocka, S.G. Deans, M. Asztemborska and S. Hart, Differences in bioactivity between the enantiomers of $\alpha$-Pinene. Journal of Essential Oil Research, 11, 393-397 (1999).

13. H. Al-Kateb and D.S. Mottram, The relationship between growth stages and aroma composition of lemon basil Ocimum citriodorum Vis. Food Chemistry, 152, 440-446 (2014).

14. M.L. Ruiz del Castillo, M.M. Caja, G.P. Blanch and M. Herraiz, Enantiomeric distribution of chiral compounds in orange juices according to their geographical origins. Journal of Food Protection, 66, 1448-1454 (2003).

15. P. Dugo, C. Ragonese, M. Russo, D. Sciarrone, L. Santi, A. Cotroneo and L. Mondello, Sicilian lemon oil: composition of volatile and oxygen heterocyclic fractions and enantiomeric distribution of volatile components. Journal of Separation Science, 33, 3374-3385 (2010).

16. I. Bonaccorsi, D. Sciarrone and A. Cotroneo, Enantiomeric distribution of key volatile components in Citrus essential oils. Brazilian Journal of Pharmacognsosy, 21, 841-849 (2011).

17. L. Mondello, M. Catalfamo, A. Cotroneo, G. Dugo, G. Dugo and H. McNair, Multidimensional capillary GC-GC for the analysis of real complex: Part IV. Enantiomeric distribution of monoterpene hydrocarbons and monoterpene alcohols of lemon oils. Journal of High Resolution Chromatography, 22, 350-356 (1999).

18. J. Bain, Morphological, anatomical, and physiological changes in the developing fruit of the Valencia orange, Citrus sinensis (L) Osbeck. Australian Journal of Botany, 6, 1-23 (1958).

19. M. Cercós, G. Soler, D.J. Iglesias, J. Gadea, J. Forment and M. Talón, Global Analysis of gene expression during development and ripening of citrus fruit flesh. A proposed mechanism for citric acid utilization. Plant Molecular Biology, 62, 513-527 (2006).

20. G. Schomburg, E. Bastian, H. Behlau, H. Husmann, F. Weeke, M. Oreans and F. Müller, Selective and non-selective sampling from precolumn separations - with emphasis on the sampling of aqueous solutions. Journal of High Resolution Chromatography, 7, 4-12 (1984).

21. C. Bicchi, A. D’Amato, V. Manzin, A. Galli and M. Galli, Cyclodextrin derivatives in the gas chromatographic separation of racemic mixtures of volatile compounds X. 2,3-Di-O-ethyl-6-O-tert.-butyldimethylsilyl- $\beta$ - and $-\gamma$-cyclodextrins. Journal of Chromatography A, 742, 161173 (1996).

22. Z. Wang, A. Huang, Y. Sun and Z. Sun, Cyclodextrins as buffer additives for the enantiomeric separation of pinacidil in capillary zone electrophoresis. Journal of Chromatography A, 749, 300-303 (1996).

23. C. Bicchi, A. D'Amato and P. Rubiolo, Cyclodextrin derivatives as chiral selectors for direct gas chromatographic separation of enantiomers in the essential oil, aroma and flavour fields. Journal of Chromatography A, 843, 99-121 (1999).

24. J.M. Guadayol, J. Caixach, J. Ribé, J. Cabañas and J. Rivera, Extraction, separation and identification of volatile organic compounds from Paprika Oleoresin (Spanish Type). Journal of Agricultural and Food Chemistry, 45, 1868-1872 (1997).

25. G.B. Nickerson and S.T. Likens, Gas chromatography evidence for the occurrence of hop oil components in beer. Journal of Chromatography A, 21, 1-5 (1966).

26. E. Liberto, C. Cagliero, B. Sgorbini, C. Bicchi, D. Sciarrone, B.D. Zellner, L. Mondello and P. Rubiolo, Enantiomer identification in the flavour and fragrance fields by 'interactive' combination of linear retention indices from enantioselective gas chromatography and mass spectrometry. Journal of Chromatography A, 1195, 117-126 (2008).

27. A.C. Aprotosoaie, M. Hăncianu, I.-I. Costache and A. Miron, Linalool: a review on a key odorant molecule with valuable biological properties. Flavour and Fragrance Journal, 29, 193-219 (2014).

28. F. Augusto, A. Leite e Lopes, and C.A. Zini, Sampling and sample preparation for analysis of aromas and fragrances. TrAC Trends in Analytical Chemistry, 22, 160-169 (2003).

29. M. Kreck, A. Scharrer, S. Bilke and A. Mosandl, Enantioselective analysis of monoterpene compounds in essential oils by stir bar sorptive extraction (SBSE)-enantioMDGC-MS. Flavour and Fragrance Journal, 17, 32-40 (2002).

30. L. Maignial, P. Pibarot, G. Bonetti, A. Chaintreau and J.P. Marion, Simultaneous distillation - extraction under static vacuum: isolation of volatile compounds at room temperature. Journal of Chromatography A, 606, 87-94 (1992).

31. H. Casabianca, J.B. Graff, V. Faugier, F. Fleig and C. Grenier, Enantiomeric distribution studies of linalool and linalyl acetate. A powerful tool for authenticity control of essential oils. Journal of High Resolution Chromatography, 21, 107-112 (1998).

32. B. Bonnländer, R. Cappuccio, F.S. Liverani and P. Winterhalter, Analysis of enantiomeric linalool ratio in green and roasted coffee. Flavour and Fragrance Journal, 21, 637-641 (2006). 
33. A. Cotroneo, A. Verzera, G. Lamonica, G. Dugo and G. Licandro, On the genuineness of citrus essential oils. Part X. Research on the composition of essential oils produced from sicilian lemons using 'pelatrice' and 'sfumatrice' extractors
34. M.L. Ruiz del Castillo and G. Dobson, Influence of stage of ripeness on the enantiomeric distribution of chiral terpenes in blackcurrant fruits (Ribes nigrum L. Journal of Food Science, 67, 3284-3288 (2002). 